\title{
Zona incerta: A link between the visual cortical sensory system and the brainstem motor system
}

\author{
ROBERT THOMPSON and MICHAEL K. BACHMAN \\ Louisiana State University, Baton Rouge, Louisiana 70803
}

\begin{abstract}
The zona incerta is known to receive a contingent of fibers from the occipital cortex. To test whether this subthalamic region plays a differential role in visually guided behavior, adult albino rats, trained on both a visual pattern discrimination problem and an equally difficult nonvisual (incline plane) discrimination problem, sustained lesions to the zona incerta and were subsequently tested for retention. Significant retention deficits were observed only on the visual problem. These results suggest that the occipitoincertal pathway is selectively involved in visually guided behavior.
\end{abstract}

It has repeatedly been found that bilateral removal of the visual cortical areas abolishes retention of visual pattern discrimination habits in rats, while bilateral destruction of the more anterior portions of the cerebrum (including the motor cortex) has little or no effect (Horel, Bettinger, Royce, \& Meyer, 1966; Lashley, 1950; Thompson, 1969). These results, coupled with others (Myers, Sperry, \& McCurdy, 1962; Voneida, 1967), suggest not only that certain brainstem motor sites are involved in the initiation and control of learned responses to visual signals, but that the visual cortex (and/or adjacent visual "association" areas) may send important conduction pathways to these brainstem sites.

One such brainstem site may be the subthalamus. Of special interest is the finding that the zona incerta, which is an integral part of the subthalamus, receives a contingent of fibers from the occipital cortex (Nauta \&.Bucher, 1954). It is also important to note that the subthalamus together with the corpus striatum, red nucleus, and substantia nigra constitute the so-called extrapyramidal motor system.

In a recently published monograph (Thompson, 1978), it was reported that extensive damage to the subthalamus impairs retention of a variety of visual and nonvisual habits in the rat. A reanalysis of the lesion placements, however, disclosed that damage to the subthalamic nucleus and subjacent cerebral peduncle appears to be responsible for the diffuse effects, whereas damage to the zona incerta alone appears to produce selective effects on visual habits. This observation provided the impetus for the current experiment, which was aimed at ascertaining the selective role of the zona incerta in visual discrimination performance.

\section{METHOD}

Subjects

Twenty adult male albino rats of the Wistar strain were used.
Prior to original learning, each animal was anesthetized and a stainless steel safety pin holding a piece of iridescent tape was secured to the auricles. This device served to monitor the animal's movements in the dark during training on the nonvisual problem (Howze, 1974).

\section{Apparatus}

A two-choice discrimination box, utilizing the motive of escape-avoidance of footshock, was employed to establish the horizontal-vertical discrimination habit (Thompson, 1978). Two pairs of stimulus cards were used in the apparatus. One pair (two medium gray cards) was employed in training the animals to push aside a card in order to obtain access to the goalbox. The second pair consisted of a horizontal black and white striped card and a vertical black and white striped card, the striations being $1.27 \mathrm{~cm}$ thick.

A single-unit T-maze adapted for the use of the escape-avoidance motive was employed to establish the incline plane (nonvisual) discrimination habit (Thompson, 1978). The maze was mounted on a platform that could be tilted $11^{\circ}$ from the horizontal axis. This apparatus was located in a lightproof room, and all training trials were conducted in total darkness.

\section{Procedure}

Ten animals were trained on the visual problem first, followed by training on the nonvisual problem. The remaining 10 animals learned the two problems in the reverse order.

With respect to the visual problem, an approach response to the unlocked horizontally striped card admitted the rat to the goalbox, whereas an approach response to the locked vertically striped card (an error) was punished by mild footshock. The position of the positive card varied from the right to the left window in a prearranged "random" order. Eight trials were given daily with an intertrial interval of $60 \mathrm{sec}$. The criterion of learning consisted of at least 15 correct responses within 2 consecutive days.

Concerning the nonvisual problem, an approach response to the upward sloping arm led to an end box which was enterable by the displacement of an unlocked card, whereas an approach response to the downward sloping arm led to a locked card, preventing the animal from entering the end box on that side. Punishment for errors was given by charging the grid section located below the locked card. The position of the correct arm was varied from the right to the left side in a prearranged random order. As in the case of the visual problem, eight trials were given daily with an intertrial interval of $60 \mathrm{sec}$, and the criterion of learning consisted of at least 15 correct responses within 2 successive days. 
Following learning of the two problems, 10 rats sustained lesions to the zona incerta. The remaining 10 animals served as the shamoperated control group, undergoing the same surgical procedures as the experimental group, save for drilling of the skull and insertion of the lesion electrode. The retention test was given 14 days after surgery and consisted of relearning the two problems in the order in which they were originally mastered.

\section{Surgery and Histology}

All operations were carried out under deep chloral hydrate anesthesia. Destruction of the zona incerta was accomplished electrolytically by passing a constant anodal current of $2.0 \mathrm{~mA}$ for a duration of $10 \mathrm{sec}$ through an implanted stainless steel electrode with $1.0 \mathrm{~mm}$ of the tip exposed. With reference to a modified version of the Massopust rat atlas (Thompson, 1978), the stereotaxic coordinates were as follows: $2.9 \mathrm{~mm}$ anterior, $2.5 \mathrm{~mm}$ lateral, and $7.0 \mathrm{~mm}$ ventral.

After the retention test was completed, each experimental animal was killed with an overdose of chloral hydrate, its vascular system perfused with normal saline followed by $10 \%$ Formalin, and the brain removed and stored in 10\% Formalin for 2 days. Each brain was sectioned frontally at $90 \mu$ with the use of a freezing microtome. Every third section showing the lesion was subsequently photographed by using the section as a negative film on an enlarger (see Thompson, 1978).

\section{RESULTS}

Table 1 shows the learning and relearning error scores for each animal. For our purposes, statistical treatment of the data was accomplished with the use of the Mann-Whitney test for independent samples and the Wilcoxon test for related samples (Siegel, 1956). First of all, it is important to point out that the two problems were virtually of equal difficulty. The visual problem was learned after an average of 16.3 errors as compared to an average of $\mathbf{1 7 . 7}$ errors for the nonvisual problem. This difference fell considerably short of statistical significance. (Although the control animals tended to learn the two problems more efficiently than the experimental animals preoperatively, the differences were not statistically significant.) Retentiveness of the two problems was also similar. The control group averaged 1.4 relearning errors on the visual problem as against an average of .9 relearning errors on the nonvisual problem; this difference likewise fell short of statistical significance.

With respect to the experimental group, significantly more relearning errors were made on the visual problem than on the nonvisual problem $(\mathrm{p}<.01)$. Of equal importance was the finding that the experimental group was significantly inferior to the control group in retention of the visual problem $(p<.02)$, but not in retention of the nonvisual problem $(p>.10)$.

All experimental animals, except two, sustained lesions to the zona incerta at the level of (or slightly posterior to) the subthalamic nucleus (Figures 1A, 1B, and 1C). Rats 1 and 3, however, suffered lesions which were anterior to the subthalamic nucleus (Figure 1D). As shown in Table 1, these two animals were the only ones of the experimental group that showed excellent retention of the visual habit. Conceivably, the incertal focus for visual discrimination deficits may lie within the posterior division of the

Table 1

Individual Learning and Relearning Errors on the Visual (V) and Nonvisual (N) Habits

\begin{tabular}{|c|c|c|c|c|c|}
\hline \multirow[b]{2}{*}{ Rat } & \multirow[b]{2}{*}{ Sequence } & \multicolumn{2}{|c|}{ Visual Habit } & \multicolumn{2}{|c|}{ Nonvisual Habit } \\
\hline & & Learn & Relearn & Learn & Relearn \\
\hline & & \multicolumn{4}{|c|}{ Experimental Rats } \\
\hline 1 & VN & 15 & 0 & 19 & 0 \\
\hline 2 & VN & 16 & 25 & 12 & 3 \\
\hline 3 & VN & 16 & 2 & 24 & 3 \\
\hline 9 & $\mathbf{V N}$ & 17 & 10 & 12 & 0 \\
\hline 11 & VN & 16 & 13 & 19 & 0 \\
\hline 6 & NV & 21 & 20 & 26 & 4 \\
\hline 7 & NV & 14 & 14 & 18 & 5 \\
\hline 8 & NV & 39 & 41 & 12 & 4 \\
\hline 12 & NV & 18 & 12 & 28 & 3 \\
\hline 13 & NV & 15 & 21 & 19 & 0 \\
\hline \multirow[t]{2}{*}{ Mean } & & 18.7 & 15.8 & 18.9 & 2.2 \\
\hline & & \multicolumn{4}{|c|}{ Control Rats } \\
\hline 4 & $\mathbf{V N}$ & 9 & 3 & 20 & 0 \\
\hline 10 & VN & 15 & 0 & 12 & 0 \\
\hline 18 & $\mathbf{V N}$ & 8 & 0 & 12 & 3 \\
\hline 19 & VN & 10 & 0 & 15 & 0 \\
\hline 20 & $\mathbf{V N}$ & 22 & 2 & 21 & 3 \\
\hline 5 & NV & 17 & 3 & 16 & 0 \\
\hline 14 & NV & 19 & 0 & 19 & 0 \\
\hline 15 & NV & 14 & 0 & 17 & 0 \\
\hline 16 & NV & 9 & 1 & 15 & 0 \\
\hline 17 & $\mathbf{N V}$ & 17 & 5 & 19 & 3 \\
\hline Mean & & 14.0 & 1.4 & 16.6 & .9 \\
\hline
\end{tabular}

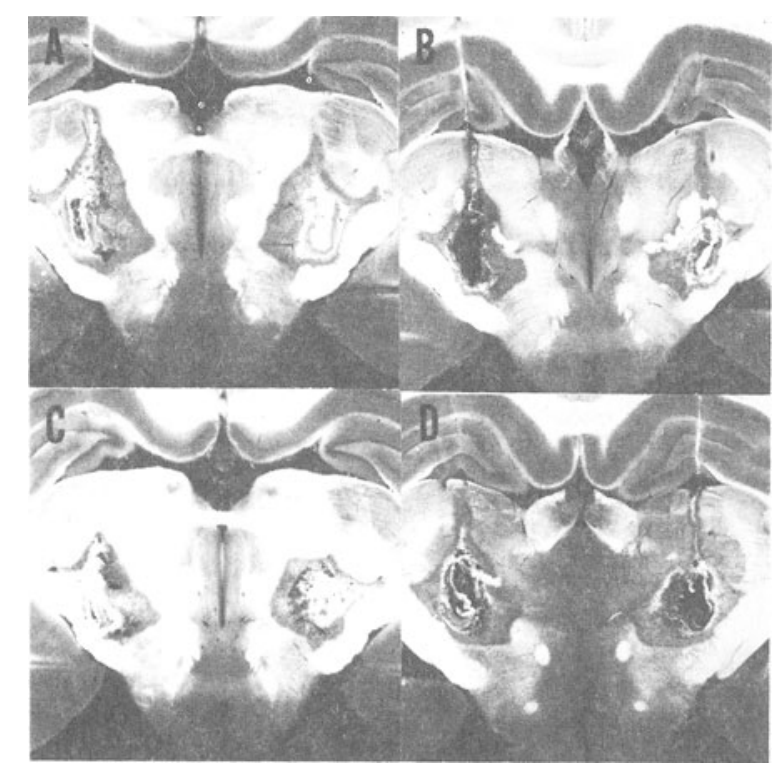

Figure 1. Photographs of unstained sections showing incertal lesions in rats 11(A), 6(B), 13(C), and $1(D)$. 
subthalamus. In no case did the lesions of any experimental animal invade the lateral geniculate bodies or the optic tracts. Similarly, the subthalamic nucleus and the cerebral peduncle were largely spared. ${ }^{1}$

\section{DISCUSSION}

The key finding of this study, of course, centers on the selective deleterious effects of incertal lesions on the visual habit; 7 of the 10 experimental animals made at least four times as many errors on the visual problem as on the nonvisual problem. By virtue of the occipital efferents to the zona incerta (Nauta \& Bucher, 1954) and the latter's connectivity with other components of the basal ganglia (Knook, 1965), it is certainly tempting to conclude that the occipitoincertal pathway constitutes one important link in the chain between the reception of visual signals and the production of an adaptive response, at least with respect to the albino rat.

Other explanations, however, cannot be entirely ruled out. Our lesions to the zona incerta, for example, invaded the overlying medial lemniscus and ventrobasal thalamus. This raises the possibility that the visual deficit reported in the current experiment arises from damage to structures other than the zona incerta. While one of us failed to observe visual deficits in the presence of lesions to the lateral portions of the medial lemniscus and ventrobasal thalamus (Thompson, 1976), further study of this diencephalic zone seems warranted. Even if it is granted that the critical site of our lesions lies within the zona incerta, the subthalamus, like the adjacent medial forebrain bundle, is a funnel through which many ascending and descending fiber systems pass (Knook, 1965). Conceivably, interruption of one of these fiber systems by our incertal lesions may be responsible for the observed visual deficit. If some fiber system other than that originating within the occipital cortex is involved, it very likely does not arise from the ventral nucleus of the lateral geniculate bodies or the superior colliculus. Recent studies have failed to demonstrate pattern discrimination disturbances in the presence of lesions to either of the foregoing components of the visual system (Legg \& Cowey, 1977; Thompson, 1969).

Finally, the finding that our incertal lesions did not totally abolish the rat's capacity to relearn the pattern discrimination habit raises the possibility that multiple links exist between the visual cortical sensory system and the brainstem motor system. Although this possibility may not be very appealing, it does provide the basis for accounting for the results of earlier experiments suggesting that occipitoreticular (Howze, 1974; Petit \& Thompson, 1974; Thompson \& Craddock, 1972) and occipitostriate (Livesey \& Muter, 1976) pathways may also contribute to pattern discrimination performance in rats.

\section{REFERENCES}

Horel, J. A., Bettinger, L. A., Royce, G. J., \& Meyer, D. R. Role of neocortex in the learning and relearning of two visual habits by the rat. Journal of Comparative and Physiological Psychology, 1966, 61, 66-78.

Howze, M. A. The lateral cerebral peduncle: Its functional significance for the acquisition of visual and kinesthetic discriminations in the rat. Physiological Psychology, 1974, 2, 500508.

KNook, H. L. The fiber-connections of the forebrain. Philadelphia: Davis, 1965.

LASHLEY, K. S. In search of the engram. Symposia of the Society for Experimental Biology, 1950, No. IV, 454-482.

LEGG, C. R., \& Cowey, A. The role of the ventral lateral geniculate nucleus and posterior thalamus in intensity discrimination in rats. Brain Research, 1977, 123, 261-273.

Livesey, P. J., \& MUter, V. Functional differentiation within the neostriatum of the rat using electrical (blocking) stimulation during the discrimination learning. Journal of Comparative and Physiological Psychology, 1976, 90, 203-211.

Myers, R. E., Sperry, R. W., \& MCCurdy, N. M. Neural mechanisms in visual guidance of limb movement. Archives of Neurology, 1962, 7, 195-202.

Nauta, W. J. H., \& Bucher, V. M. Efferent connections of the striate cortex in the albino rat. Journal of Comparative Neurology, 1954, 100, 257-286.

Petit, T. L., \& Thompson, R. Nucleus cuneiformis lesions: Amnestic effects on visual pattern discrimination in the rat. Physiological Psychology, 1974, 2, 126-132.

SIEGEL, S. Nonparametric statistics for the behavioral sciences. New York: McGraw-Hill, 1956.

Thompson, R. Localization of the "visual memory system" in the white rat. Journal of Comparative and Physiological Psychology Monograph, 1969, 69, 1-29.

Thompson, R. Stereotaxic mapping of brainstem areas critical for memory of visual discrimination habits in the rat. Physiological Psychology, 1976, 4, 1-10.

Thompson, R. A behavioral atlas of the rat brain. New York: Oxford University Press, 1978.

Thompson, R., \& Craddock, S. N. Lateral cerebral peduricle lesions: Amnestic effects on a visual habit in the rat. Psychonomic Science, 1972, 27, 140-142.

Voneida, T. J. The effect of pyramidal lesions on the performance of a conditioned avoidance response in cats. Experimental Neurology, 1967, 19, 483-493.

\section{NOTE}

1. Our rats with incertal lesions typically recovered eating and drinking habits within $48 \mathrm{~h}$ after surgery. Aside from a hyperresponsiveness to tactile stimuli and a transient disturbance in the control of the hindlegs, they appeared quite normal.

(Received for publication May 29, 1979; revision accepted August 7, 1979.) 